This is an Accepted Author Manuscript of an article published by Elsevier in Journal of Environmental Psychology, volume 5, issue 2, 1985

\title{
COMPARATIVE FLOORPLAN-ANALYSIS AS A MEANS TO DEVELOP DESIGN GUIDELINES
}

\author{
HERBERT VAN HOOGDALEM, THEO J. M. VAN DER VOORDT and \\ HERMAN B. R. VAN WEGEN
}

\author{
Centre for Architectural Research, Delft University of Technology, Department of \\ Architecture, Berlageweg 1,2628 CR Delft, The Netherlands
}

\begin{abstract}
This study explores the usefulness of comparative floorplan-analysis for the develop-ment of spatio-organizational concepts in architectural design processes.

Each floorplan can be considered as a reflection of the goals and activities of the users as interpreted by the architect. By comparing a wide range of building layouts for similar organizations one may achieve a good understanding of the way organizational characteristics are (can be) expressed in spatial solutions. In the study reported here, in which 50 Dutch health centres were analysed com-paratively, definite relationships between organizational and spatial concepts were found. This information is used both as a means to make organizational principles more explicit as well as data for briefwriting and design guidelines.
\end{abstract}

\section{Introduction}

One of the major functions of a building is the spatial organization of social activities. Designing an adequate building therefore requires information about its users, their goals, expectations, activities and organizational structure. Designing itself is part of organization. Usually principals lack the capability to translate organizational needs into spatial requirements. Briefs are often roughly developed and incomplete. Visiting one or two buildings of similar organizations to generate ideas and spatial concepts is usually not satisfactory. First, it is not clear how to select representative buildings and second, how to recognize the relevant differences and their (dis)advantages. The same holds true for architects. They are often committed to their own experiences and specialist literature. With regard to the foundation of user requirements in particular the literature of the behavioral and management sciences may be useful. However, as Weidemann and Anderson (1978) have pointed out, many designers find this research literature difficult to use, because design implications are 'buried' in jargon-filled text or seem to be totally missing. Besides, architects are much more oriented to visual representations rather than verbal notes. This may lead to the so-called applicability gap. To bridge the gap we need well elaborated design guides, based on research and focussed on the implication of different spatial concepts and patterns of spatial relationship from several points of view, e.g. behavioral consequences such as privacy and efficiency. Several design guides have been developed for quite different edifices: (van der Voordt and van Wegen, 1983; van der Voordt et al., 1984; Reference Notes 


\section{H. van Hoogdalem et al.}

1, 2 and 3) which have proved to be very useful in practice, for example to

(1) gain a better insight in the spatial requirements to be elaborated in a brief,

(2) develop alternative design concepts and spatial solutions,

(3) test the utility of (interim) plans or the usefulness of an existing building for renovation or adaptation.

\section{Design guidelines for Dutch Health Centres}

In the past few years, changing ideas about health care facilities in The Netherlands have led to the development of multidisciplinary cooperation teams. Health centres, in which at least three basic disciplines-general practitioner, social worker and health visitor-cooperate under one roof, have passed through a rapid development from only a few centres in 1970 to over a hundred in 1984 and their number is still growing.

This rapid growth causes an increasing demand for information about possible organizational settings and their favourable physical surroundings. For this reason the Dutch Ministry of Public Health and Social Welfare developed guidelines for the space-requirements of health centres (Reference Note 4). Essentially these guidelines specified for a given health team size, the number of rooms and room sizesin square metres, adding 50\% to these nett areas to obtain the gross area to be built and subsidized for a particular health centre. Within these restrictions any health team is free to subdivide and organize the space as they think will fit best their particular purposes. Although these guidelines are of great importance to designers, users and others who are concerned with the design and exploitation of health centres, they are at the same time criticized because a lot of information is not so much based on systematic research as on expert opinion. Furthermore the committee specifies space standards only. Information about other aspects of the layout, especially the spatial implications of cooperation, are still lacking. For this reason the present inquiry was commissioned to investigate which spatial conditions best promote cooperation amongst staff in primary health care.

Aithough in the U.K. there is a lot of experience with planning and building for primary health care, the English or Scottish design guides for health centres (DHSS, 1970, 1979SHHD, 1973; Reference Note 5) are not applicable in the Dutch context without careful consideration. In the first place there are differences between staff membership and work style in the two countries. Another restriction is that most existing design guides lack information about design alternatives and their behavioural consequences in relation to different organizational models. Therefore we tried to develop a design guide for health centres, focussed on the Dutch situation.

\section{Procedure}

In order to obtain an accurate insight into the space requirements of health centres the following procedure bas been pursued.

(a) Development of a methodology for evaluation; testing several methods in a pilot study. This included questionnaires and observations, as well as sociometric and multidimensional scaling techniques.

(b) Visiting all 50 'purpose built' health centres. By means of interviews with one 
or two well informed participants and observations 'in the field' we tried to gain an insight into the ideas and motives on which the building layout was based and its present functioning.

(c) Comparative analysis of all 50 floorplans (i) to test the floor area guidelines of the Department of Heaith in actual buildings, (ii) to discover differences and similarities in patterns of spatial relationships, i.e. the way spaces are arranged and linked, and types of communal use of space.

(d) Development of a classification of health centres on the basis of organizational and spatial characteristics.

(e) Development of criteria for selection of a representative sample per building type for further research.

(f) Detailed case studies of the centres selected in (e). In four centres representatives of all professional disciplines were interviewed with respect to their ideology on cooperation with other disciplines, their tasks and work style and whether the building is an adequate spatial answer to its purpose in relation to building layout, sizes of spaces and so on. Furthermore we presented some design alternatives which were developed in (c) and asked the users to comment on these. The design process has been reconstructed by analysing records from several archives and by interviewing people who were involved in producing the building, including the architect. Some patients were also interviewed.

(g) Distribution of questionnaires among staff members and patients in all other centres visited. The staff were asked to judge the sizes of their own spaces and the relations between these spaces. The questionnaires for the patients were focussed on aspects such as accessibility of the building, wayfinding, privacy and confidentiality and their overall opinion of the building.

In addition to these post occupancy evaluations we checked the literature on health centres(e.g. Canter and Canter, 1979; Deal, 1976; Beales, 1978; British Medical Association, 1966; Stone, 1980; Cammock, 1981; Cox and Groves, 1981; Reference Notes 6-9) and interviewed a number of experts in the field of primary health care to gain insight into recent developments and expectations for the future.

The methodology and the results of this broad inquiry have been described in four research reports (Reference Note 10). It is not our intention to enter into all methodological aspects of the project and its results in the present article. The present paper focusses on the usefulness of comparative floorplan-analysis and its role in this inquiry.

\section{What Can be Read From Floorplans?}

Floorplans are abstractions from the real buildings. Such important aspects as the fabric the building is made of, its constructional system, its colors and finishes, the type of installations for heating, ventilation, lighting, etc. and its costs are usually left out. These aspects deserve attention in any complete building evaluation study, and a comparative approach can be very useful (Reference Note 11).

On the other hand floorplans do provide essential information on the most permanent parts of the building (its 'shell' and structural grid, see Duffy, 1974) whereas most of the above mentioned others parts have shorter life-cycles.

In the second place, fioorplans embody the social nature of the building, through 


\section{H. van Hoogdalem et al.}

which it localizes people and modulates their interaction (Hillier and Leaman, 1976; Lipman and Harris, 1980; Hillier and Hanson, 1984).

A floorplan drawing of all 50 purpose built health centres which were visited in the course of the project were obtained. For each space or room on these drawings it was noted by whom, when and for what activity it was used. Assuming that each floorplan reffects the spatial outcome of a complex social process, during which a group of future users and their architect must take all kinds of decisions from different points of view, this set of 50 floorplans does represent a potentially rich source of 'historical data' (Duffy and Worthington, 1975). In essence each drawing is a new configuration of more or less the same basic elements, i.e. rooms or spaces for specific activities which are performed in every health centre. Each configuration is the specific, time and place-bound answer to a particular organizational problem. At first sight the variation between the floorplans seemed bewildering, but on closer investigation it appeared to be possible to distinguish a smaller number of typical configurations or types of solutions. The search process for basic solutions was of an interactive and iterative nature. On the one hand the search was guided by hypotheses, questions and notions suggested by experts in the field of primary health care, in the literature and by our own hunches. On the other hand the plans themselves generated ideas and hypotheses which were subsequently checked in the material. The same floorplans were studied from many points of view. These points of view represent the many facets to be considered when briefing and designing a building. By so doing for any identified problem a number of concrete integral design solutions could be traced in the documented floorplans.

\section{Results of the Comparative Floorplan-analysis}

Comparing floorplans is in the first place a search for similarities and differences in the way that essentially identical functions or activities are accommodated from one floorplan to another. The following variations were studied: (a) size and relative location of spaces, (b) relations between separate spaces, (c) relations between groups of spaces-zoning - and (d) communal space. The results are presented in this order and discussed later.

\section{Size and relative location of spaces}

Between different floorplans, spaces containing the same function or type of use, show an enormous variation in size. Within floorplans variation in the sizes of the same functional spaces is remarkably small, as long as spaces belonging to only one particular discipline are considered. Between disciplines within one floorplan there can be considerable variation in size. This could be explained as the result of different functional requirements of space for the different disciplines. Assuming that the space standards proposed by the Department of Health represent an impartial yardstick, whether total available space is evenly distributed over various groups it is possible to check.

Figure 1 presents the outcomes for the most frequently occurring functions, summated over 50 health centres. The following observations were made.

(1) The consulting rooms for the general practitioners vary from 12 to $26 \mathrm{~m}^{2}$, with a modal size of $17 \mathrm{~m}^{2}$. As a result, $93 \%$ of them are larger than the proposed standard of $13 \mathrm{~m}^{2}$. 


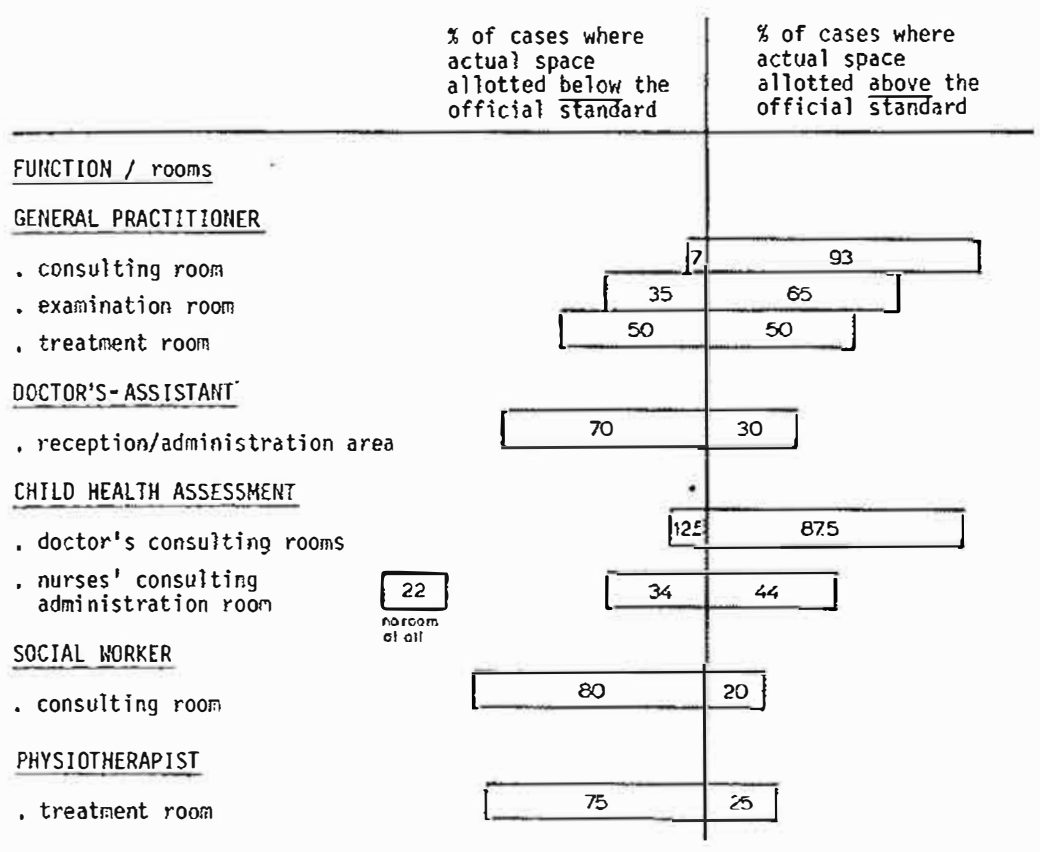

Comparison of actual and proposed square meters

FIGURE 1. Comparison of actual and proposed square metres.

(2) The reception/administration spaces, manned by the GP-assistants, also show an enormous variation between centres. For three assistants for example this total varies from less than $5 \mathrm{~m}^{2}$ to $30 \mathrm{~m}^{2}$, with an average of $14 \mathrm{~m}^{2}$, whereas the standard proposes $21 \mathrm{~m}^{2}$.

(3) Social worker's consulting rooms vary from $8 \mathrm{~m}^{2}$ to $29 \mathrm{~m}^{2}$, with an average of $15 \mathrm{~m}^{2}$ against a standard of $18 \mathrm{~m}^{2}$. Taken over all 50 floorplans GP-assistants' and social workers' workspaces are $70 \%$ and $80 \%$, respectively, smaller than recommended in official guidelines.

(4) The consulting rooms for paediatricians have a modal size of between 16 and $17 \mathrm{~m}^{2}$, whereas the nurse's room has a modal size of $12 \mathrm{~m}^{2}$ (excluding those health centres where there is no nurse's room). For both staff members the guideline proposes $13 \mathrm{~m}^{2}$.

The results show that doctors have accommodation above the proposed area, while doctors' assistants, nurses, social workers and physiotherapists occupy a smaller area than proposed.

With regard to the location of spaces within the building, the floorplans demonstrate a similar picture. The spaces located along the façade were analysed. They receive natural light and ventilation and permit their users to have a view to the outside. Spaces located internally are without these highly valued characteristics. In $62 \%$ of the floorplans reception/administration areas were located internally, the same for $37 \%$ of the physiotherapy treatment spaces. Waiting areas are in $50 \%$ of the cases internal, as were $48 \%$ of the treatment rooms of the general practitioner. 


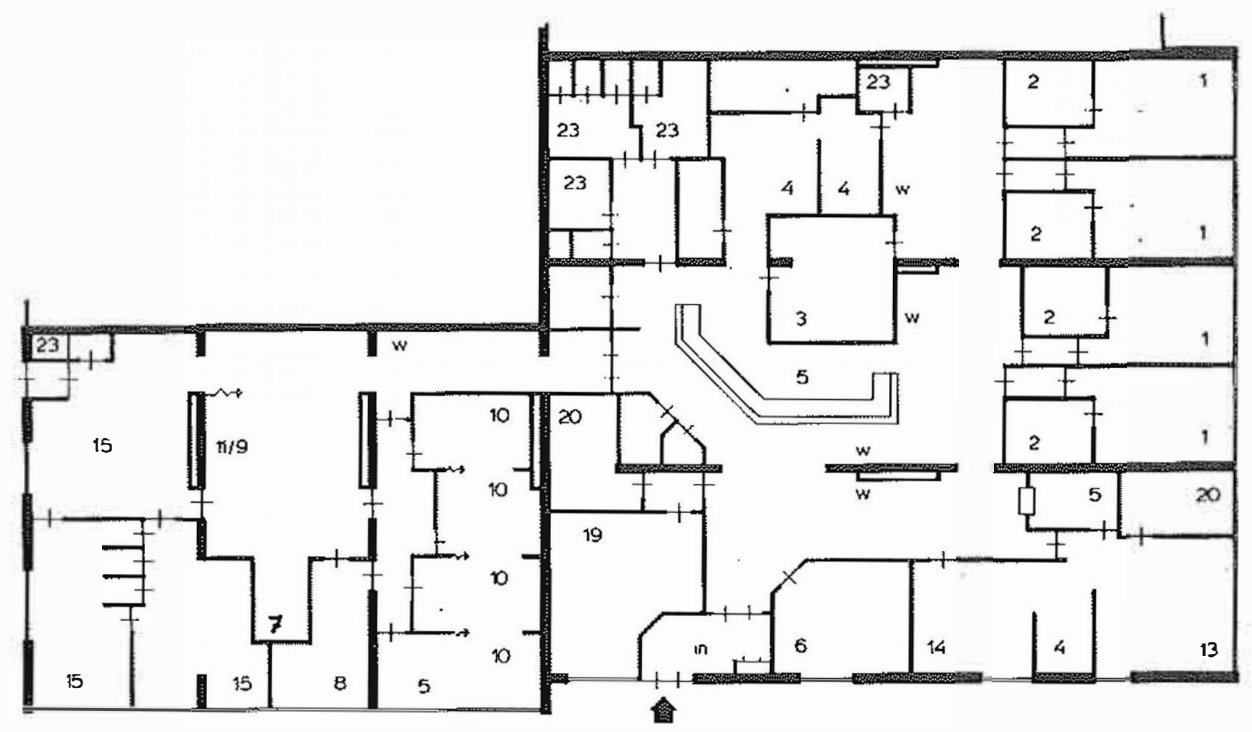

FigurE 2. Merenwijk Health Centre in Leiden. The GPs and the dentists are located in attractive places, whereas the physiotherapists and the district nurse have a less favourable allotment of space. Note the lack of zoning, e.g. Iraffic between GPs and assistants (both staff zones) passes right across the waiting area (public zone). Key: 1 = consulting room (GP), 2 = examination room (GP), $3=$ treatment room (GP), $4=$ laboratory, $5=$ reception and records, $6=$ social worker, $7=$ Child Health Care/Nurse, $8=$ Child Health Care/Doctor, $9=$ Child Health Care/Children's dressing room, $10=$ treatment room physiotherapy, $11=$ practice room physiotherapy, $12=$ cubicle, $13=$ dental surgery, $14=$ oral hygiene, $15=$ medical officer, $16=$ pharmacy, $17=$ loan equipment $/$ storage, $18=$ wash room, $19=$ common room, $20=$ pantry $/ k i t c h e n, 21=$ locker room, $22=$ disposal room, $23=$ toilet, $24=$ engineering services, $25=$ office, $w=$ waiting area.

To illustrate the above data in an actual floorplan, the floorplan of the Merenwijk Health Centre in Leiden is a rich example (Figure 2). This centre is accommodated in a building, which was planned originally for shops. This meant that there were relatively few windows available. Furthermore, the building was enclosed on three sides by other premises, leaving only one outer façade with a favorable view out and natural lighting.

The larger than standard rooms of the GPs and the dentist can be found along this façade. Substandard spaces for district nurses and physiotherapy are located internally, as is the reception and administration area. Social workers, CHApaediatritions, local authority doctors and nurses, are all located along the less favorable façades.

\section{Relations between spaces}

Subdivision and separation of spaces. Two or more activities which in one floorplan are accommodated in one room, are performed in two or more separate rooms in other floorplans with a varying degree of separation between these rooms. Two examples will be given to illustrate this variation. In 41 of the 50 health centres there is a physiotherapy department.

In Table 1 these 41 practices are presented according to the type of separation between treatment spaces they show. In type $I$, every treatment space, serving one 
TABLE 1

Separation of spaces within the physiotherapy area

\begin{tabular}{l}
\hline IIIIIII \\
Period in which premises \\
were built
\end{tabular}




\section{H. van Hoogdalem et al.}

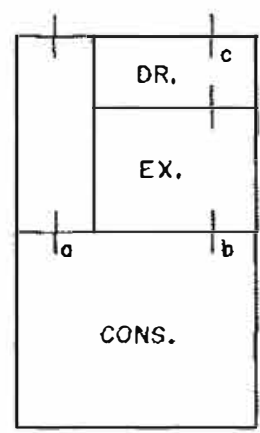

Type $A(N=10)$

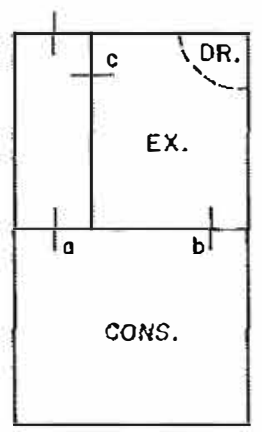

Type $B(N=35)$

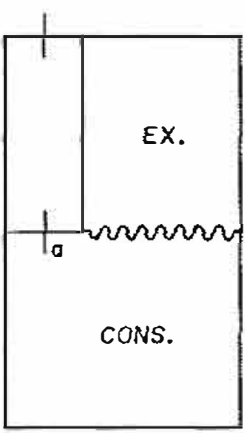

Type C $(N=5)$

Figure 3. Subdivision and separation of spaces within the GP area.

physiotherapist and one patient at a time, is surrounded by solid walls and the space can be closed by a door. In type $I I$ treatment spaces take the form of cabins, surrounded on three sides by solid walls or semi fixed partition walls, the space can be shut by a curtain or folding door. In type III each treatment space is surrounded by curtains, which can be drawn to make one large open space if necessary. Looking at the periods in which the practices were built it looks as if there is a weak trend, in more recent premises, towards the acoustically better isolated type I and combinations of type I and II treatment cabins.

Another example of varying separation is that between the consulting and examination spaces of the GP. In Figure 3 the three basic types with their frequency of occurrence are depicted. In type $A$ the suite is subdivided into a dressing cubicle (DR.), an examination space (EX.) and a consulting space (CON.), all surrounded by solid walls, containing heavy soundproof doors. In type B the dressing cubicle has disappeared, but sometimes a curtain can be drawn to separate a dressing space. In type $\mathrm{C}$ the solid wall with a door between examination and consulting space has been replaced by a curtain or a high bookshelf. Door $\mathrm{c}$ has disappeared as well. In the Discussion section we will return to the meaning and purpose of this variation.

Patterns of spatial relationships. A further step in the analysis was to look for patterns in the relationships between separate rooms. A useful way to describe relational patterns are graphs. A recent book by Hillier and Hanson (1984) gives an ingeniously elaborated set of graph applications and operations for the description and analysis of settlement- and building-layouts. In the rather elementary graph used here each separate room is represented by a dot. Connections between rooms are represented by lines between these dots. The resulting patterns can easily be compared.

For all the disciplines such graph representations were made. Here only the results of the Child Health Assessment Department will be given. A typical session of this department proceeds as follows.

Mothers arrive with their babies in prams. Leaving these prams in a waiting space, they bring their babies to a large room, the 'boxes-room', named after the boxshaped undressing cubicles along the walls. After being undressed the baby is weighed and measured by a district nurse or her assistant in a more or less screened off part 
TABLE 2

Patterns of spatial relationship within the child health assessment

\begin{tabular}{lcccccccc}
\hline & \multicolumn{8}{c}{ Relational pattern } \\
\cline { 2 - 8 } $\begin{array}{l}\text { Period in } \\
\text { which premises } \\
\text { were built }\end{array}$ & A & B & C & D & E & F & G \\
\cline { 2 - 8 } & bo-dn do dn do dn do & do dn do dn dodn & & \\
\hline 1972 & - & - & 3 & 3 & - & - & - & 6 \\
$1973-1976$ & 2 & 2 & 2 & 4 & 2 & 1 & - & 13 \\
$1977-1980$ & 11 & 6 & 1 & 1 & 1 & - & 1 & 21 \\
Total & 13 & 8 & 6 & 8 & 3 & 1 & 1 & 40 \\
\hline
\end{tabular}

aAbbreviations used: do, doctor's consulting room; dn, district nurses consulting room; box, boxes-room.

of the boxes-room. Then mother and baby wait to be seen by a district nurse and/ or doctor, whose consulting rooms are usually directly adjacent to the boxes-room. In Table 2 the various relational patterns between the boxes-room, the doctor's consulting room and the district-nurse's consulting room, to be found in 40 health centres, are listed.

A solid line indicates that two rooms have a common wall with a door connecting both rooms directly. The absence of a line between two rooms means that both rooms are indirectly connected, via one or more other spaces. Of the listed patterns, pattern D represents those $20 \%$ cases in which the district nurses have no separate room but only the (more or less) screened off part of the boxes-room described above. In the same table we have related these patterns to the age of the building and it appears that during the last ten years there has been a shift from patterns $\mathrm{C}$ and $\mathrm{D}$ towards patterns $\mathrm{B}$ and, especially, A.

The shift towards a separate consulting room for the district nurse and/or direct connections between this room and the doctor's consuiting room and the boxesroom suggests organizational changes which will be discussed later.

\section{Relations between groups of spaces: zoning}

In the sense it is used here, the concept of zoning refers to a particular combination of a spatial area or set of spaces and a set of social rules regulating admission to and/or particular behavior in that space. As such, it is a spatioorganizational concept. Cammock (1975) has distinguished three different zones in a health centre.

(1) The public, i.e. the patients on arrival, are usually confined to a limited zone which is clearly signposted, furnished with chairs, magazines, ashtrays and an umbrella stand, and is often overlooked by a member of staff.

(2) The staff, who usually enter the building by a different door from the public, carry out their administrative duties in a 'back-stage' zone which is out of bounds to patients, so that, among other things, there is no risk that the confidential messages and reports they are handling will be seen or heard by patients.

(3) Interaction between the two categories takes place in a third zone, the joint use zone. There the members of the public become individual patients with problems and members of the staff become individual doctors, nurses or receptionists trying to solve them. It is there that most of the confidential material is generated. 
In order to enable the building to be maximally supportive of 'confidentiality', Cammock essentially makes four design recommendations:

(1) provide separate 'staff', 'joint use' and 'public' zones,

(2) provide separate entrances to the 'public' and to the 'staff' zones,

(3) provide separate routes between, on the one hand, 'staff' and 'joint use' zones and, on the other hand, between the 'public' and the 'joint use' zones, and

(4) there should be no direct relation between 'public' and 'staff' zones.

These recommendations are graphically summarized in a 'zoning pattern' in Figure 4.

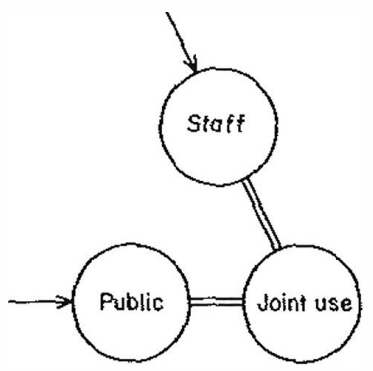

FIGURE 4. The zones of a health centre svith their links and the building entrances (Canmock, 1975).

Since the use or function of every space in the floorplans was known, each space could be assigned to one of the three categories 'public', 'joint use' and 'staff'. Therefore it was possible to test how far this 'zoning pattern' did apply in the Dutch health centre floorplans. The results were as follows.

In no floorplan was a clearly bounded, internally connected grouping of all 'staff' or of all 'joint use' spaces found. Rather, smaller blocks of 'joint use' and 'staff' spaces, each block linked to a particular disciplinary team, were found dispersed all over the floorplans. The 'staff' spaces within these blocks, like reception/administration rooms and laboratories, have very frequently also a 'joint use' character in that patients are invited there. Real 'at all times only staff' spaces are generally not located within these team blocks or territories, but mostly are directly accessible from public circulation space, a situation conflicting with recommendation (4) above.

With a few exceptions, separate staff entrances, leading to a backstage 'staff' zone are lacking. Those few exceptions found were more likely planned as emergency exits.

The above finding, that real 'staff only' spaces hardly occur within the dispersed team blocks, changed the straightforward test of this recommendation into the question 'Are there routes from one "joint use" space to other "joint use" spaces, which do not pass through "public" spaces?' The results for five different disciplines are given in Table 3. The results indicate that only in the physiotherapy department is there a general separation between 'public' (i.e. waiting space) and 'joint use' (i.e. treatment space) zones. The low percentage of separate 'joint to joint' routes for the social worker is an artefact, due to the fact that in many health centres only one social worker consulting room is present. 
TABLE 3

Types of routes and the concept of zoning

\begin{tabular}{lccccc}
\hline & \multicolumn{5}{c}{ Disciplinary team (\%) } \\
\cline { 2 - 5 } & GP & GP-assistant & CHA & $\begin{array}{c}\text { Social } \\
\text { worker }\end{array}$ & $\begin{array}{c}\text { Physio- } \\
\text { therapist }\end{array}$ \\
\hline $\begin{array}{l}\text { From joint to joint } \\
\text { only through public }\end{array}$ & 46 & 25 & 38 & 81 & 6 \\
$\begin{array}{c}\text { Partly through public (i.e. } \\
\text { some routes but not all) }\end{array}$ & 14 & 19 & 3 & - & - \\
$\begin{array}{c}\text { From joint to joint } \\
\text { not through public }\end{array}$ & 40 & 56 & 59 & 19 & 94 \\
\hline
\end{tabular}

\section{Communal space}

In order to be recognized and to be subsidized as an official health centre, the different disciplinary teams have to sign an agreement to cooperate, and to facilitate and express this cooperation, they have to be housed 'under one roof', as is the literal translation of the Dutch stipulation 'onder een dak'.

It was a point of special interest to see how this cooperation was reflected in the floorplans. More specifically it was expected that this cooperation would express itself most clearly in the communal use of the same spaces by different disciplines.

Following again Cammock's distinction, three options for communal use of space were at hand:

(a) communal use of public spaces, such as entrances, circulation space, waiting areas, public toilets, etc.;

(b) communal use of joint spaces like consulting and treatment rooms; and

(c) communal use of staff spaces, like meeting- and coffee-rooms, kitchens and utility spaces like staff toilets.

It appeared that communal use of type (b) occurred more or less in all health centres, but mainly by workers of disciplines who are only participating on a part-time basis in the health centre, such as dieticians, psychologists and midwives. Such disciplines use either a general purpose consulting room or the consulting rooms of the GPs, the social workers or the district nurses for several hours per week.

Since the guidelines of the department made a strong plea to combine functions and activities into one space, especially those needing a lot of space such as antenatal relaxation exercises and physiotherapy exercises, it was expected to find more of this type of communal use of 'joint use' in the floorplans. Because this recommendation was followed up in only a few centres, there were hardly any reflections of this practice in the floorplans. With few exceptions, most health centres have a meeting room, often an annex, a kitchen or a pantry, used by all disciplinary teams. However, it was found that the spatial organization of the public spaces particularly showed great variation between the floorplans with respect to the number of entrances, reception desks, waiting areas and type of circulation area. It became evident that three basic building types can be distinguished, with an increasing degree of communality (Figure 5 ). 
(a)
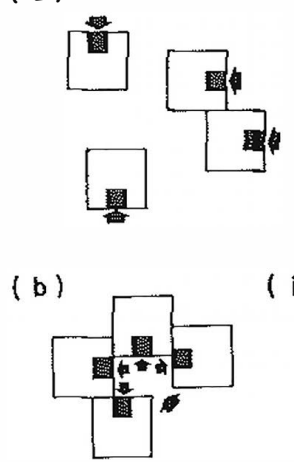

(i)

(ii)
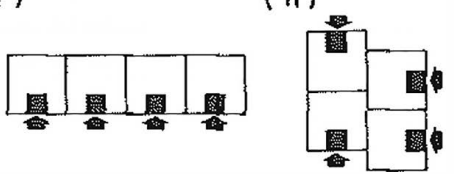

(i)

(ii)
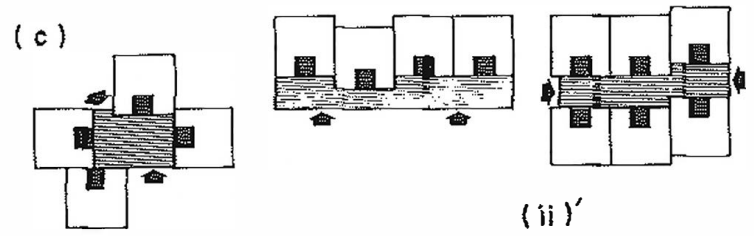

(ii)

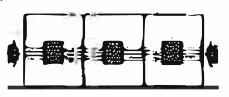

(iv)

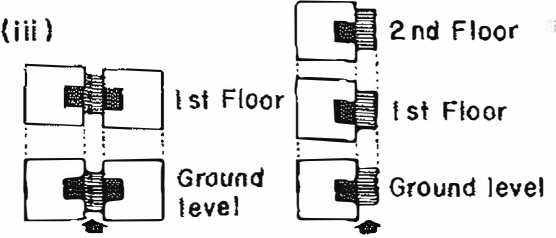

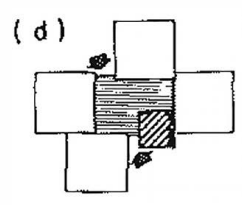

(i)
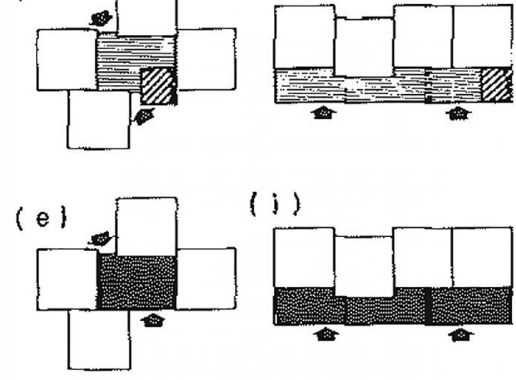

(i)

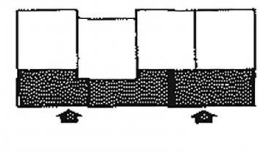

(ii)

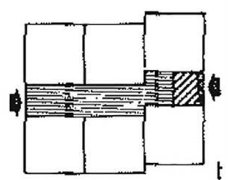

(ii)

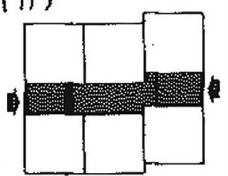

$\square$ Workroom

Wats Waiting areo

国 Circulation areo

Waiting/circulation comblned

Entrance from the outside

Figure S. Three basic spatio-organizational types with different spatial layouts for each functional type. (a) Type I. (b) Type I'; with layouts (i) and (ii). (c) Type II: with layouts (i), (ii), (ii)', (iii) and (iv). (d) Type III with layouts (i) and (ii). (e) Type III' with layouts (i) and (ii).

Type I. In type I (Figure 5(a)) there is a physical subdivision of the building in detached blocks. Communality is limited to the combined location of different disciplines on one spot. Each block has its own entrance, reception desk (if present) and waiting area. A variant of this type (type $I^{\prime}$, see Figure $5(\mathrm{~b})$ ) is characterized by a grouping of several blocks with shared walls. Sometimes these blocks are arranged next to each other (e.g. in a street), in other cases they are arranged around a courtyard. The Dauwendale-Health Centre in Middelburg is an example of type I' (Figure 6). Essential for this type is that the circulation paths between the disciplines are located in the open air. Such centres look like shopping centres: together yet apart (see Figure 7). 
(a)
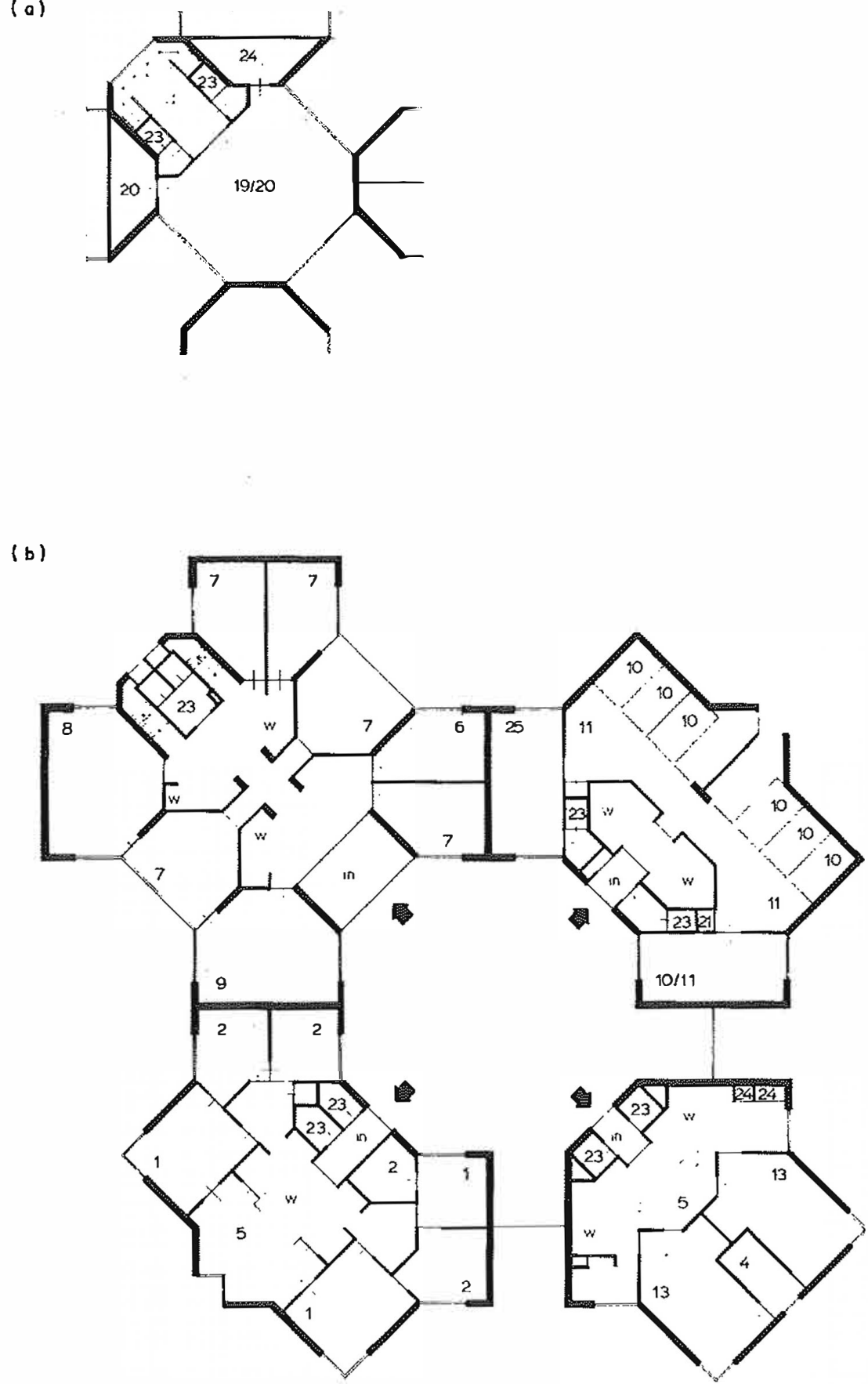

Figure 6. Dauwendaele Health Centre in Middelburg, example of type $I^{\prime}$. (a) First floor. (b) Ground floor. Separate blocks per discipline, each with its own entrance, reception and waiting area. The common room for meetings, etc., is located on the first floor of the child health care unit. Note the internal spatial configuration of the physiotherapy, with an emphasis on efficiency. For key, see Figure 2. 


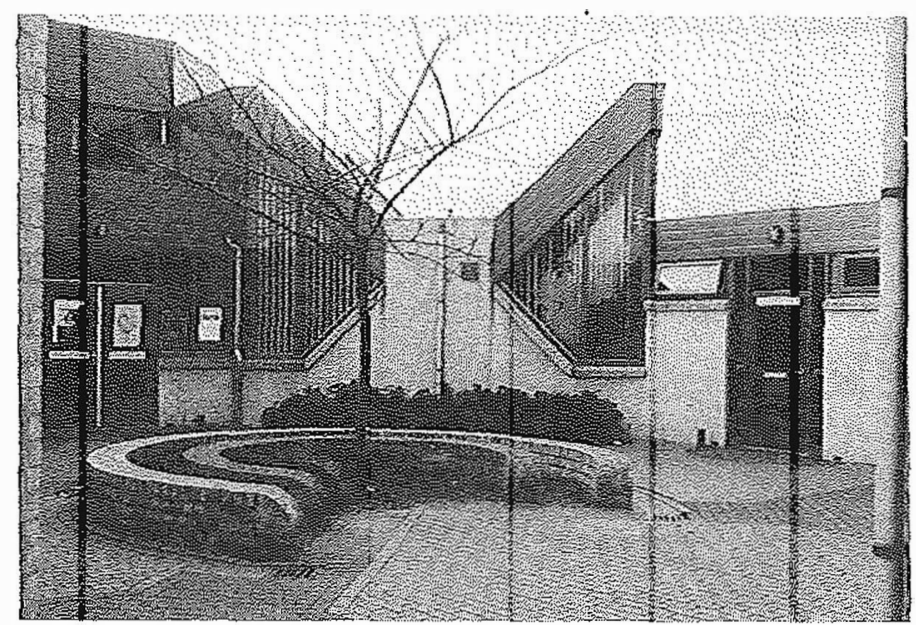

Figure 7. Dauwendacle Health Centre in Middelburg (type $I^{\prime}$ ). View into the common courtyard. Left: Entrance to Child Health Assessment and District Nurses department, on top of which the communal staff meeting room. Right: The entrance to the physiotherapy.

Type II. In type II (Figure 5(c)) there is still physical subdivision of the building into different blocks - horizontally into floors or vertically into wings - and most of the disciplines have their own waiting area, but now the blocks are accessible from one shared and interior circulation area. An example of type II is given in Figure 8 (see also Figure 9).

Type III. Finally, type III (Figure 5 (d) is characterized by one shared waiting area and a lot of shared circulation space, without subdivision by inner doors into separate compartments. In some centres waiting and circulation are separated, in other centres these two functions are combined into one shared area (type III',) see Figure 5(e); see Figure 10 for an example).

Once these three basic types were identified, it appeared that 45 of the 50 floorplans belonged to one of these types. The other five showed characteristics of two types. Not surprisingly it appeared that this 'hybrid' buildings were all built in several stages, mostly as extensions to already existing buildings. The distribution of the floorplans over the three types is given in Figure 11.

Type, size and form. The three types differ with regard to variables such as size of the building, team size and spatial arrangement of the blocks and the workrooms within these blocks. For instance, small teams are often housed in type III premises whereas in type I premises both small and larger team sizes are found (Figure 11). Also there is a manifest correlation between team sizes, size of the building and degree of integration or differentiation of space. The majority of small buildings have one entrance with one communal reception area, whereas larger centres often have a main entrance with one or more additional doorways and several reception desks. So a large-scale organization corresponds with a large-sized building and an increasing differentiation of space into more or less self supporting parts. As a matter of course in each type there may be a different spatial configuration too. The various units of which a centre consists can be grouped together 
(a)

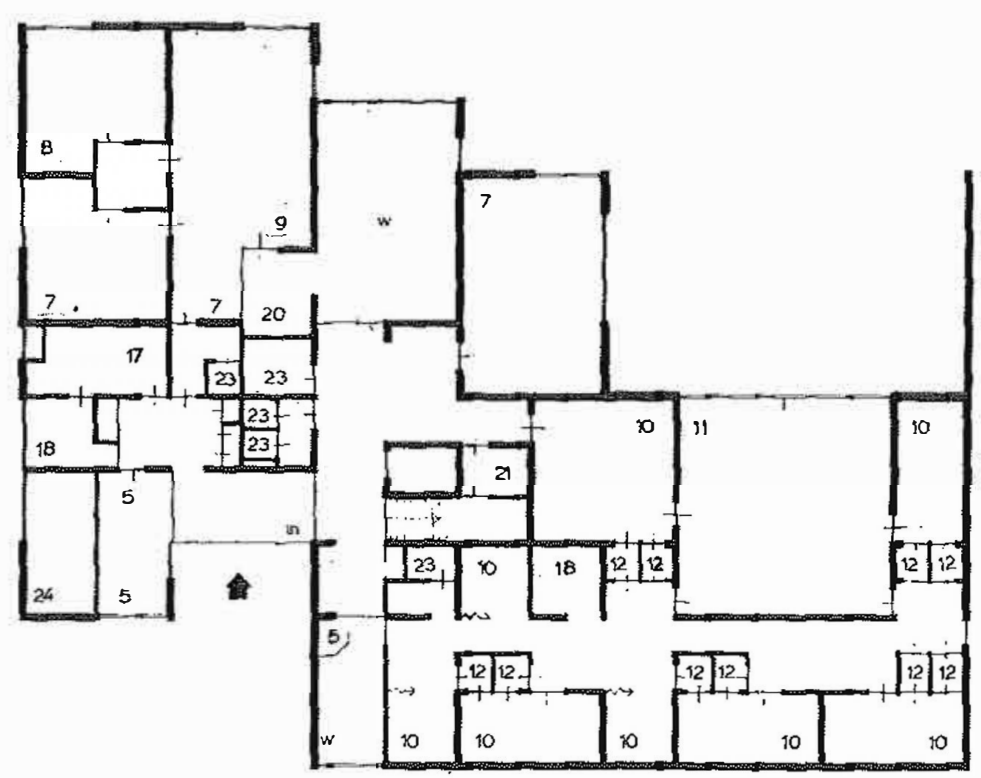

(b)

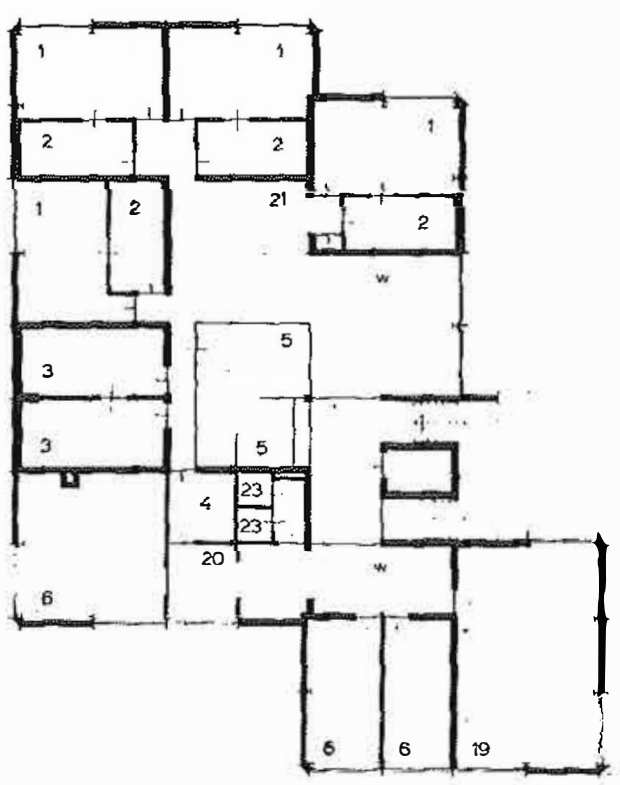

Figure 8. Maarssen, example of type II. (a) Ground floor, (b) First floor. Location of workrooms along corridors, with clearly recognizable blocks per discipline, each with its own internal entrance, waiting- and circulation area. Note the spatial layout of the physiotherapy, with an emphasis on privacy and personal care. For key, see Figure 2.

around a central hall ('centroid type'), along corridors ('linear type') or by a combination of both systems (Figure 5). It was found that each building type can be designed in different forms, but a centroid configuration occurred especially in small buildings of functional type III or III'. 


\section{H. van Hoogdalem et al.}

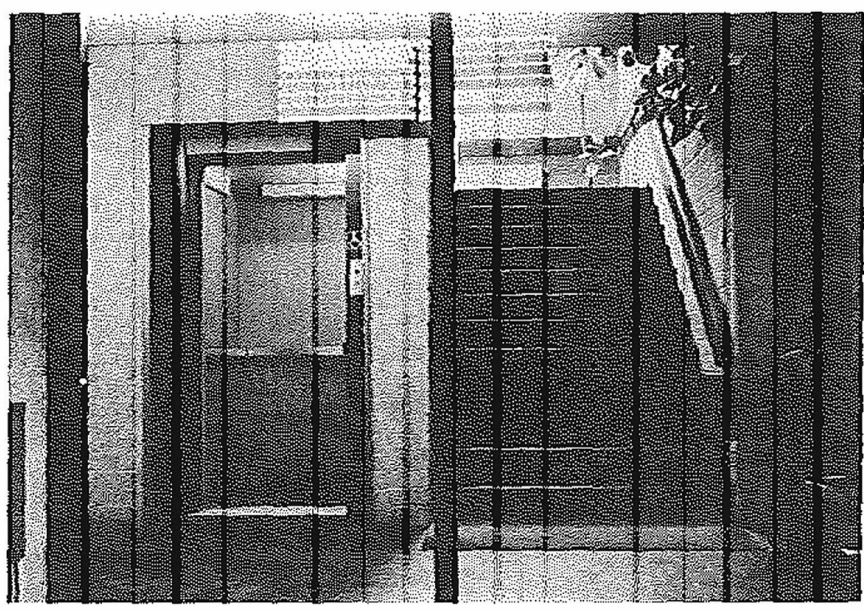

FIGURE 9. Maarsen Heaith Centre (type II). Upon entering this building the visitor does not meet a receptionist, but a great monitor of signs and routing leading him to the various disciplinary teams.

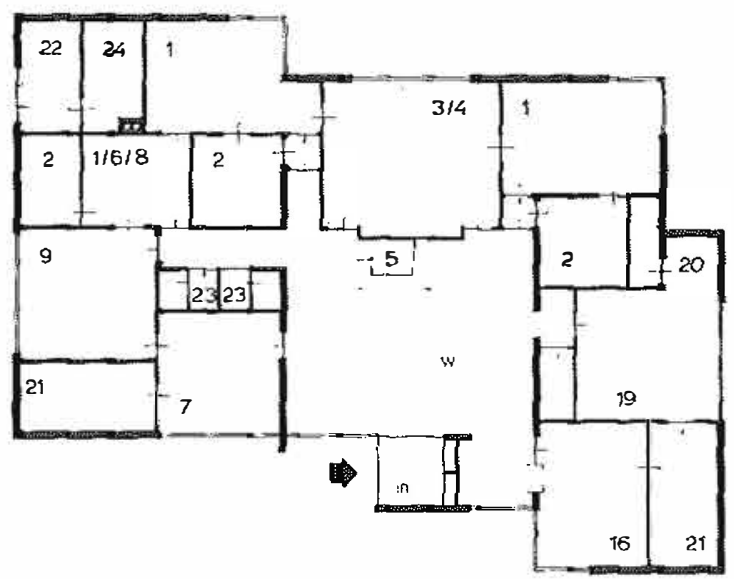

FioURE 10. Kerkrade, example of type III'. Location of workspaces around a communal hall with a clear 'pivot' point. At the overall level of the building there is a lack of zoning, most staff-staff traffic passes through public area. In the GP-unit the zoning principle has been applied successfully. Note the distribution of space: the GPs (being originators and principals of the centre) are altotted a very attractive part of the cake, whereas the social worker and the district nurse are less fortunate. For key, see Figure 2.

\section{Discussion}

The results of the comparative floorplan-analysis will be discussed against the background of other relevant research and results obtained by the other methods employed in this project. It should be emphasized that floorplan-analysis, though highlighted in this article, acquires its full relevance only when used in conjunction with these other methods. Decoding floorplans may lead to misinterpretations. Many foorplans reflect also the personal interpretation of the brief by the architect with his or her own architectural ideology. Besides, other conditions such 


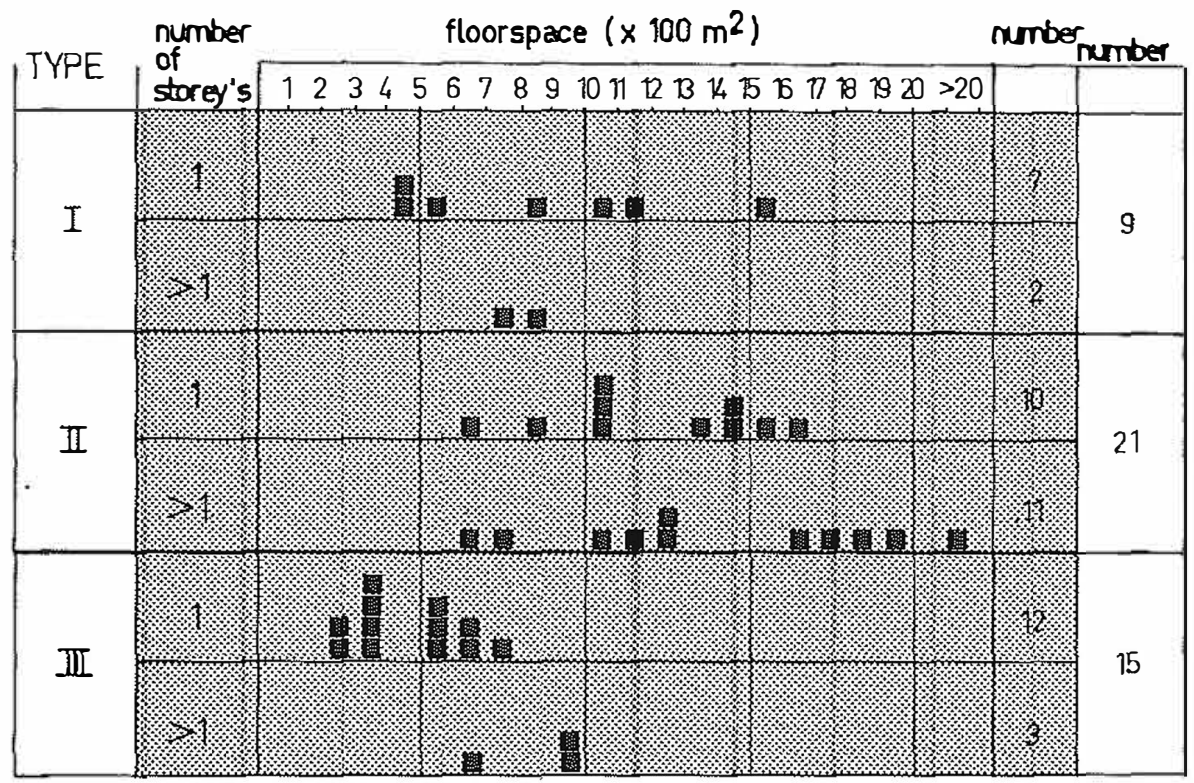

FIGURE 11 Relationship between type and size ( $\mathrm{m}^{2}$ and number of storeys). In this diagram the miscellaneous types are excluded.

as financial restrictions, governmental procedures and town-planning aspects may blurr the relation between organizational requirements and spatial outcomes. The historical reconstruction of the design process in the case studies proved to be especially vital for a good understanding of the actual floorplan and its present functioning, as it appeared from the post-occupancy evaluation.

\section{Size and relative location of spaces}

Comparing the actual sizes of the various rooms with the sizes proposed in the Department of Health Guidelines, systematic differences between the two were found. It should be noted that these guidelines were prepared by a committee of official representatives of all professional disciplines. Depending mainly on their own professional experience and checking this within their professional group, each representative had come to an estimate of types, numbers and sizes of needed workspaces. For some disciplines, e.g. GPs and the Child Health Assessment Department, there already existed design guidance and documentation, for other disciplines, e.g. social workers and physiotherapists, such information was not available. So, for example, the physiotherapy standards for health centres were based on the operations and sizes of physiotherapy departments in general hospitals.

This last example shows that in general the committee placed hardly any restrictions on the space demands put forward by each discipline. In that sense, the distribution of space by the committee could be called fair and egalitarian.

Conceiving of space as a scarce commodity (see Lipman et al., 1978) the results can be explained as the consequence of relative power: within disciplines, of the GP over his assistants, of the paediatrician over the district nurse; between disciplines, of the more powerful and better informed GPs and 'District Health Care' 


\section{H. van Hoogdalem et al.}

over the younger and less well organized disciplines of social work and physiotherapy. Testimony to this difference is that quite often either the GPs or the District Health Care Organization own the building, while the other disciplines rent their spaces. From the reconstruction of the design process in the case studies it appeared that doctors played an especially dominant role in the design teams, in taking the initiative and in briefing the architect.

Results from the post-occupancy evaluation by GPs and their assistants suggest the often dysfunctional outcome of this powerplay. Doctors are generally satisfied with the size of their consulting room where as more than one-third of the assistants judge their administration and reception area as (much) too small (Tables 4 and 5). Add to this lack of space, the lack of view to outside and the lack of daylight and natural ventilation inherent to the internal location of many of these spaces, and it becomes clear that status differences express themselves quite clearly in different spatial conditions, as has been shown for offices (Duffy, 1974; Lipman et al., 1978; Reference Note 12).

TABLB 4

Evaluation of the consulting room size by the GPs $(N=33)$

\begin{tabular}{|c|c|c|c|c|c|c|c|c|}
\hline \multirow[b]{2}{*}{ Judgement } & \multicolumn{8}{|c|}{ Size of consulting room $\left(\mathrm{m}^{2}\right)$} \\
\hline & 12 & 13 & 14 & 15 & 16 & 17 & $\geqslant 18$ & Total \\
\hline Much too small & - & - & - & - & - & - & - & 0 \\
\hline Too small & - & 1 & - & - & - & 3 & - & 4 \\
\hline 'OK' & 2 & 2 & 2 & 7 & 5 & 7 & 4 & 28 \\
\hline Too large & 一 & - & - & 1 & - & - & - & 1 \\
\hline Much too large & - & - & - & - & - & - & - & 0 \\
\hline Total & 2 & 3 & 2 & 8 & 5 & 10 & 4 & 33 \\
\hline
\end{tabular}

TABLE 5

Evaluation of the reception/administration area by the GPs assistants $(N=31)$

\begin{tabular}{lcccccccc}
\hline & \multicolumn{7}{c}{ Size of reception/administration area $\left(\mathrm{m}^{2}\right.$ per assistant $)$} \\
\cline { 2 - 9 } Judgement & $\leqslant 3$ & 4 & 5 & 6 & 7 & 8 & $\geqslant 8$ & Total \\
\hline Much too small & 1 & 1 & - & 1 & - & - & - & 3 \\
Too small & 3 & 1 & 1 & 1 & - & 1 & 1 & 8 \\
'OK' & 2 & 1 & 2 & 6 & 2 & - & 7 & 20 \\
Too large & - & - & - & - & - & - & - & - \\
Much too large & - & - & - & - & - & - & - & 31 \\
$\quad$ Total & 6 & 3 & 3 & 8 & 2 & 1 & 8 & 3 \\
\hline
\end{tabular}

Subdivision and separation of spaces

The floorplan-analysis showed wide variations in the degree and mode of separation of similar functions between health centres. It appeared that especially different perceptions of the client's need for privacy and the staff's need for efficiency explain these differences. A comparison between the physiotherapy departments of Middelburg and Maarssen, both investigated in a case-study, illustrates these different perceptions and their design implications quite clearly (Figures 6 and 8).

In Middelburg seven physiotherapists (four full time equivalents) have a total area 
of $128 \mathrm{~m}^{2}$ at their disposal, including waiting space, sanitary facilities, etc. In Maarssen, five physiotherapists (also four full-time equivalents) have almost double this space, $250 \mathrm{~m}^{2}$.

In Middelburg, efficiency is strongly emphasized: short walking distances, all physiotherapists using the same pool of instruments and apparatus, linen cupboard, communal room for administration, etc. The corridor is also used as an exercise space for clients. The need for patient privacy, both visual and auditory, is not felt to be very important: the majority of clients being children or patients whose complaints have a clearly physical cause, e.g. fractures which need revalidation.

In Maarssen, client privacy has been the dominant motive. There the physiotherapists strongly believe that many so-called physical complaints are caused, aggravated or, at least, accompanied by social and psychological problems. Creating a confidential atmosphere encourages patients to talk freely about their problems. They seek the advice of other disciplines like social workers and general practitioners to find a multidisciplinary treatment of the 'holistically' defined prob-. lems. Not surprisingly, such interdisciplinary approaches are not sought by the Middelburg physiotherapists.

These different therapeutic conceptions are reflected in the floorplans. In Middelburg there is one open space, that can be converted by curtains into a number of very small treatment cubicles, in which patients undress, lie or sit down. Walking exercises, needing more space, take place in the circulation area. In this way several patients can be treated at the same time, sometimes by the same physiotherapist. At regular times all curtains are drawn away, so that the open space can be used for antenatal relaxation exercises.

In sharp contrast to this flexible open plan design stands the Maarssen Health Centre, where every physiotherapist has a personal treatment room, surrounded by solid brick walls. Two of them are isolated from the circulation space by separate undressing cubicles for the outgoing and incoming patients. In the other cases these cubicles are so located that they divide the long circulation area in smaller, more 'private' sections. Every treatment room contains a wash basin, lockers, a table for administration and for personal belongings of the physiotherapist. Further, its length permits walking exercises. Exercises needing more space and group activities can be performed in the larger, extra high, communal exercise room. Despite its considerable size, the total area of Maarssen is still within the margins set by the official guidelines. However, as noted, these were based on hospital standards for physiotherapy practice. Various solutions to separate consulting and examination spaces of the General Practitioners reflect a similar conflict between efficiency and privacy (Figure 3).

In earlier Dutch design recommendations (Reference Note 7), the provision of a separate examination room with soundproof doors, a and b, was strongly recommended as a time saving solution. The patient's flow can be settled then as follows. A patient is called into the consulting room through door a. When during consultation the need for closer examination arises, the patient is sent into the examination room through door $b$ and asked to undress. In the meantime door $b$ is shut and the next patient can be called into the consulting room and asked to wait, while the doctor returns to the patient waiting undressed in the examination room. Having finished examining, he asks the patient to dress and leave the room through door $\mathrm{c}$ while he returns through door $\mathrm{b}$ to the patient waiting in the con- 


\section{H. van Hoogdalem ef al.}

sulting room, etc. Technical problems with this procedure arise when patients are escorted by one or more relatives or friends. In general this pipeline-like procedure proved to be impractical and impersonal to both doctors and patients. Although door c still can be found in most health centres it is put out of use, by locking it, placing cupboards in front of it, or even sealing it permanently to improve sound isolation. The resulting relational pattern becomes the same as in type $\mathrm{C}$. However there still remain strong objections to combine consulting and examination into one room, even if they are separated by a curtain or high bookshelf. Part of the reasons are functional: some examinations require complete darkness, and odours generated by undressing should be confined to and extracted from the examination room. Another reason is that consulting and examination activities require a completely different 'décor': consulting either in a 'businesslike office' surrounding or in a more informal 'living-room'-like atmosphere, whereas undressing and examination are more associated with and possibly facilitated by a clinical, 'bathroomlike' atmosphere. Since 'you don't undress in an office or livingroom', clear separation of these two atmospheres seems to be desired by most GPs and their patients.

\section{Relations between separate spaces}

As was illustrated by the third door in the GPs suite, the absence or presence of doors in floorplans, their intended and actual use, can be most telling about organizational procedures and changes therein. The shifts noticed in the results for the Child Health Assessment Department reflect a major change in procedures within the CHA sessions (Table 2). This shift is known as the transition from 'Old Style' to 'New Style'. In the 'Old Style' CHA sessions, district nurses acted merely as an assistant to the paediatrician. They received the mothers and babies in the boxes room, measured the weight and length of the child and noted these data. Further her task was to keep order and hygiene. The real examining, testing and consulting was to be done by the doctor. In practice however mothers did not wait for the doctor and started to consult the district nurse. Since these 'premature' consultations often became confidential and emotional and could be overheard by the other mothers waiting, one can find, especially in the older centres, attempts in the form of (glazed) screens to create some privacy for these types of spontaneous consultations.

During the last decade the profession of district nurse has been markedly upgraded. Factors like prolonged and more specialized training, the introduction of male nurses, the change of the District Nurses Organization from voluntary, charitable bodies into state subsidized professional organizations all played their role. One outcome of this process is that in the 'New Style' CHA sessions the district nurses play a much more important role. They do the major part of the consulting, testing and examining, while the paediatrician, less frequently present, performs specialized medical examinations and consultations. The foorplans of the more recently built health centres reflect this greater autonomy of the district nurses, in that they now have their own fully separated consulting room, often directly connected with the paediatricians room by a door, as there are mutual consultations. In the briefing stage of the Leiden Health Centre (Figure 2) the interests of the CHA were guarded by an older district nurse, brought up in the 'Old Style' tradition. When construction was well underway, the younger generation protested fiercely 
(8) Cammock, R. (1977). Utilization of Consulting Suites in Health Centres. Medical Architecture Research Unit, Polytechnic of North London.

(9) Cammock, R. (1979). Utilization of Treatment Suites in Health Centres and Group Practices. Medical Architecture Research Unit, Polytechnic of North London.

(10) Hoogdalem, H. van, Voordt, D. J. M. van der and Wegen, H. B. R. van (1981/1983). Ruimtelijk Finctionele Analyse yan Gezondheidscentra. Deel I t/m IV. Technische Hogeschool Delft, afd. Bouwkunde. (Spatio-functional analysis of health centres, part I-IV).

(11) Hoogdalem, H. van and de Jonge, H. (1984). Evaluatie-onderzoek Gezondheidscentra Almere. (Evaluation of Health Centres in Almere). Delf:: Technische Hogeschool Delft, afdeling Bouwkunde.

(12) De Wolf, T. D. J. and Henning, D. N. (1980). Office Space: Analysing Use and Estimating Needs, Public Works, Canada.

\section{References}

Beales, J. G. (1978). Sick Health Centres and How to Make Them Better. Kent: Pitman Medical Publishing Co Ltd.

British Medical Association (1966). Health Centres and Group Practices. Tavistock Square, London: British Medical Association.

Cammock, R. (1975). Confidentiality in health centres and group practices, the implications for design. Journal of Architectural Research, 4, 5-17.

Cammock, R. (1981). Primary' Health Care Buildings. London: The Architectural Press.

Canter, D. and Canter, S. (1979). Designing for Therapeutic Environments. A Review of Research. Chichester: John Wiley \& Sons.

Cox, A. and Groves, P. (1981). Design for Health Care. London: Butterworths \& Co.

Deal, J. M. (1976). Health centres, clinics and group surgeries. In: E. D. Mills (ed.), Planning. Building for Health, Welfare and Religion. London.

DHSS (1970), Health centres-a Design Guide. London: Her Majesty's Stationery Office.

DHSS (1979). Health Building Note, Health Centres. London: DHSS.

Duffy, F. (1974). Office design and organization. Environment and Planning B, 1, 105-118; 2, 212-236.

Duffy, F. and Worthington, J. (1977), Organizational design. Journal of Architectural Research, 6, 4-9.

Hillier, B. and Hanson, J. (1984). The Social Logic of Space. Cambridge: Cambridge University Press.

Hillier, B. and Leaman, A. (1976). Architecture as a discipline. Journal of Architectural Research, 5, 1, 28-32.

Lipman, A. and Harris, H. (1980). Environmental Psychology: a sterile research enterprise? Architectural Psychology Newsletter, X, 18-28.

Lipman, A., Cooper, I., Harris, R. and Tranter, R. (1978). Power, a neglected concept in office design? Journal of Architectural Research, 6, 28-37.

SHHD (1973). Design Guide: Health Centres in Scotland. London: Her Majesty's Stationery Office.

Stone, P. (ed.) (1980). British Hospital and Health-care Buildings. Design and Appraisals. London: The Architectural Press.

Teut, A. and Nedeljkov, G. (1973). Die Gruppenpraxis. Dusseldorf: Bertelsmann Fachverlag.

Voordt, D. J. M. van der, and Wegen, H. B. R. van (1983). Underpasses for pedestrians and cyclists. User requirements and implications for design. Transportation Planning and Technology, 8, 1-14.

Voordt, D. J. M. van der, Vrielink, D. and Wegen, H. B. R. van (1984). Kinderdaguerblijyen --Richtlijnen voor de bous"(Design-Guidelines for child care centres). Delft. Delftse Universitaire Pers.

Weidemann, S. and Anderson, J. (ed) (1978). Priorities for Enviromment Design Research. Washington D.C.: Environmental Design Research Association. 
